\title{
APLIKASI INTEGRAL DALAM BIDANG EKONOMI DAN FINANSIAL
}

\author{
Luh Putu Ida Harini ${ }^{1 \S}$, Kartika Sari ${ }^{2}$ \\ ${ }^{1}$ Program Studi Matematika, Fakultas MIPA-Universitas Udayana [Email:ballidah@unud.ac.id] \\ ${ }^{2}$ Program Studi Matematika, Fakultas MIPA-Universitas Udayana [Email:sarikaartika@unud.ac.id] \\ ${ }^{\S}$ Corresponding Author
}

\begin{abstract}
The characteristics of a function are usually investigated by looking at the continuity of the function. But what happens if a function does not have continuous properties? To what extent can the characteristics of continuous function be maintained for discontinuous cases? The stochastic function that is widely involved in solving problems in the field of average financial mathematics is a discontinuous function. This is reflected by the acquisition of a smooth curve from the modeling drawing obtained. Today, the nature of continuous functions in $[a, b]$ has been widely studied and developed. Some properties of the continuous function can be extended to the appropriate discontinuous function. In this paper, there will be some integral reviews for discontinuous functions which are closely related to stochastic functions.
\end{abstract}

Keywords: Henstock integral, Lebesgue integral, Riemann integral, stochastic function.

\section{PENDAHULUAN}

Penggunaan matematika bagi sebagian besar orang, pada awalnya terbatas pada berhitung sederhana tentang benda-benda sekitar dan sebagian besar hanya dalam penanganan masalah uang. Ilmuan pertama yang menempatkan matematika terapan ke garis depan bidang ekonomi dan keuangan adalah Loius Bachelier dalam disertasinya yang berkaitan dengan teori spekulasi (1900) yang mempelajari proses stokastik waktu kontinu tentang gerakan Brown dan penerapannya pada penetapan harga opsi. Selanjutnya Harry Markowitz pada pertengahan tahun 1950-an mempelajari pemilihan portofolio untuk memaksimalkan pengembalian dengan memegang sejumlah saham dengan mempelajari momen-momen saham dan menemukan masalah optimisasi meanvariance. Inilah titik awal tumbuhnya teori portofolio modern dengan pendekatan statistika (Tularam, 2013). William Sharpe pada saat yang sama menggunakan matematika dalam menentukan korelasi antara setiap saham dan pasar. Kemudian, Robert Merton dan Paul Samuelson mengganti model satu periode dengan waktu kontinu, model gerak Brown, dan fungsi utilitas kuadratik yang tersirat dalam optimasi mean-variance digantikan dengan peningkatan fungsi utilitas yang lebih umum. Selanjutnya lompatan besar dalam pengembangan penetapan harga opsi dilakukan oleh Fisher Black dan Myron Scholes yang menerapkan kalkulus stokastik untuk opsi yang melibatkan berbagai persamaan diferensial stokastik (PDS) yang selanjutnya menjadi era baru teori stokastik.

Seiring dengan berkembangnya terapan matematika dalam hal ekonomi dan finansial, dan untuk mencari solusinya berimbas pada pengembangan ilmu lain. Teori integral sebagai salah satu alternatif penyelesaian persamaan diferensial, yang pada awalnya dalam bidang ekonomi dan finansial hanya digunakan untuk mencari fungsi asal dari fungsi marginalnya, fungsi biaya total, fungsi penerimaan total dari fungsi penerimaan marginal, fungsi konsumsi dari fungsi konsumsi marginal, fungsi tabungan dari fungsi tabungan marginal, dan fungsi kapital dari fungsi investasi, sekarang banyak diteliti dan digunakan untuk memecahkan masalah yang terkait dengan persamaan diferensial stokastik. Teori integral merupakan 
cabang ilmu matematika analisis yang bersifat deduktif-aksiomatik dan secara teoritis masih tetap tumbuh dan berkembang dewasa ini. Akan tetapi aplikasinya terhadap masalah nyata masih belum banyak dikaji dan dikembangkan. Salah satu masalah yang akhir-akhir ini cukup banyak mendapat perhatian adalah pendekatan teori integral berkaitan dengan bidang matematika keuangan (financial). Pada bidang finansial karakteristik nilai harga saham yang berubah terhadap waktu dengan pola yang tidak terduga, menyebabkan pergerakan harga saham biasa dimodelkan sebagai proses stokastik yang salah satunya tersaji dalam suatu bentuk PDS. Selama ini PDS seringkali hanya diselesaikan dengan menggunakan menggunakan integral stokastik. Integral stokastik pada dasarnya berkembang dari integral tipe Stieltjes yang dapat menyelesaikan permasalahan $\int_{a}^{b} f(x) d g(x)$ dengan syarat fungsi $g$ bersifat bervariasi terbatas pada $[a, b]$. Pada tulisan ini akan dikaji tentang beberapa ulasan teori integral untuk fungsi diskontinu yang diaplikasikan pada model yang mendekati fungsi stokastik.

\section{METODE PENELITIAN}

Penelitian ini adalah penelitian dasar dan bersifat sangat teoritik maka tahapan seperti eksperimen untuk mendapatkan data tentu tidak akan dilakukan secara eksplisit. Penelitian diawali dengan studi literatur baik yang disajikan dalam bentuk buku, jurnal maupun laporan penelitian yang relevan dengan topik yang akan dibahas yaitu mengkaji teori integral dalam hal ini aplikasi integral dalam bidang ekonomi dan finansial. Adapun sistematika kajian pustaka yang dilakukan adalah dengan mempelajari hasil-hasil penelitian terdahulu yang terkait dengan topik yang dibahas, baik yang ada di dalam buku, jurnal maupun yang telah dibakukan dalam monograph. Pada penelitian matematika teoritik metodologi penelitian dengan sendirinya sudah termasuk di dalam proses penelitian itu sendiri melalui cara berpikir kritis dan logis, misalnya dalam pembuktian teorema atau teori. Dari hasil-hasil analisa tersebut, kemudian dikonstruksi suatu pernyataan-pernyataan baru berupa proposisiproposisi. Proses pembentukan proposisi dilakukan melalui dua cara. Pertama proposisi disusun berdasarkan hasil-hasil relevan yang telah dikutip dari tinjauan pustaka.

\section{HASIL DAN PEMBAHASAN}

Pembahasan pada paper ini akan diawali dengan mengkaji terlebih dahulu tentang teori integral yang kemudian dilanjutkan dengan pemaparan model stokastik dan persamaan diferensial stokastik yang terkait dengan dengan bidang finansial meliputi model stokastik Gerak Brown dan Model Black Scholes.

\subsection{Teori Integral}

Teori integral muncul melalui pendefinisian secara deskriptif dan konstruktif. Pendefinisian deskriptif dilakukan oleh Leibniz dan Newton dengan menggunakan anti derivatif suatu fungsi. Kemudian Bernhard Riemann secara konstruktif mengemukakan teori integral dengan menggunakan partisi, yang kemudian dikenal dengan integral Riemann. (Lee, 1989). Adanya fungsi yang tidak terintegral Riemann untuk fungsi yang bernilai 0 dan 1 mengilhami Henri Lebesgue mengembangkan integral Lebesgue yang dilakukan dengan menggunakan pendekatan teori ukuran. Integral Lebesgue dapat diaplikasikan pada fungsi terbatas yang didefinisikan pada suatu himpunan terukur berhingga (Burk, 2007). Jaroslav Kurzweil (1957) mengembangkan partisi- $\delta$ fine pada garis lurus untuk menjamin kekonvergenan barisan solusi persamaan diferensial yang telah diperoleh. Dilain pihak, karena masih banyak fungsi yang cukup bagus perumusannya tetapi tidak terintegral Riemann dan terintegral Lebesgue membawa Ralph Henstock (1960) mengembangkan integral Riemann dengan mengubah peran konstanta positif $\delta$ pada integral Riemann menjadi fungsi positif $\delta$. Karena definisi integral yang disusun oleh Henstock dan Kurzweil keduanya ekuivalen maka integral tersebut kemudian dikenal dengan integral Henstock-Kurzweil. Motivasi terbesar Henstock dalam mengembangkan integral ini adalah keinginannya untuk merumuskan suatu teori integral yang dapat digunakan untuk menyelesaikan semua permasalahan integral yang sudah ada (Lee dan Vyborny, 2000).

Selanjutnya Thomas Joannes Stieltjes yang mengembangkan integral Riemann dengan menambahkan suatu fungsi bernilai real tertentu sebagai fungsi pengintegral (integrator) mengilhami munculnya definisi integral bertipe Stieltjes. Integral Riemann 
diperluas oleh Stieltjes, menjadi integral Riemann-Stieltjes. Integral ini terdiri atas dua fungsi bernilai real pada suatu interval tertutup dan terbatas yaitu $f$ sebagai fungsi yang diintegralkan (integrand) dan $g$ sebagai fungsi pengintegral (integrator), dituliskan $\int_{a}^{b} f d g$. Dalam hal ini fungsi $g$ disyaratkan merupakan fungsi naik monoton, atau fungsi $f$ dan $g$ diasumsikan tidak memiliki titik diskontinu bersama (Rudin, 1976). Selanjutnya ditemukannya konsep himpunan fungsi bervariasi terbatas dan terbuktinya bahwa setiap fungsi yang bervariasi terbatas dapat dinyatakan sebagai selisih dua fungsi naik monoton (Lee dan Vyborny, 2000) berdampak pada perluasan teorema dari integral RiemannStieltjes dengan integrator fungsi naik monoton menjadi integral Riemann-Stieltjes dengan integrator fungsi bervariasi terbatas, dimana dengan selisihnya, integrator fungsi bervariasi terbatas selalu memberikan peranan penting untuk memberikan hasil yang lebih simetris. (Burkill, 1970). Apostol (1975) menjamin bahwa integral Riemann-Stieltjes merupakan konsep yang lebih umum dari integral Riemann, mengingat apabila fungsi integrator merupakan fungsi identitas $g(x)=x$ maka integral Riemann-Stieltjes menjadi integral Riemann. Hal ini kemudian mengilhami pembentukan definisi integral LebesgueStieltjes dan integral Henstock-Stieltjes. Integral Lebesgue-Stieltjes merupakan perluasan Riemann-Stieltjes, sehingga sifat dan teorema yang berlaku masih tetap dipertahankan (Carter dan Brunt, 2000). Kondisi ini dijamin pula oleh Horst (1984) yang menyatakan bahwa koleksi fungsi terintegral Riemann-Stieltjes merupakan himpunan bagian koleksi himpunan terintegral Lebesgue-Stieltjes. Dengan konsep generalisasi yang sama diperoleh pula bahwa koleksi himpunan terintegral Lebesgue-Stieltjes merupakan himpunan bagian himpunan terintegral Henstock-Stieltjes.

\subsection{Model Stokastik Gerak Brown}

Proses Wiener (atau gerak Brown) adalah titik awal dalam pengembangan integral stokastik (Hassler, 2016). Pada tahun 1900, Louis Bachelier memodelkan pergerakan harga saham mengikuti Gerak Brown dengan konstanta drift $\mu=0$. Pada tahun 1973, Fischer Black dan Myron Scholes mempublikasikan suatu paper tentang teori dan perhitungan opsi yang berjudul "The Pricing of Options and Corporate Liabilities".Pada gerak Brown, dapat didefinisikan sebagai gerak yang mengalami perubahan cukup singkat. Beberapa sifat penting dari gerak Brown adalah : sifat berhingga, sifat kontinu, sifat Markov, sifat Martingale, bervariansi kuadrat, dan normalitas. Sedangkan disebut gerak Brown (Brown Motion) pada proses stokastik bila berlaku ketentuan: $\quad X(0)=0 ;\{X(t), t \geq 0\}$ mempunyai kenaikan (increment) kestabilan independent dan $\quad X(t)>0$, dengan $X(t)$ berdistribusi normal rata - rata nol dan variansi $\sigma^{2}$.

\subsection{Model Black Scholes}

Model Black - Sholes dikembangkan oleh Myron Scholes dan Fischer Black pada tahun 1973. Asumsi yang mempengaruhi model Black-Scholes diantaranya adalah opsi yang dijadikan acuan ialah opsi Eropa, berlaku saat waktu habis; volatilitas (variansi harga) bersifat konstan (tetap) selama usia opsi diketahui pasti, saham yang dipakai tidak dividen dan pajak serta biaya transaksi di abaikan. Selanjutnya akan dibahas tentang Persamaan Differensial Stokastik.

\subsection{Persamaan Differensial Stokastik}

Secara umum bentuk PDS dapat diformulasikan dengan persamaan:

$$
\begin{gathered}
d X(t)=f(X(t)) d t+g(X(t)) d W(t), \\
\text { dengan } \quad X(0)=X_{0} \quad \text { dan } \quad 0 \leq t \leq T
\end{gathered}
$$

Fungsi $f(X(t))$ pada persamaan (1) merupakan suku deterministik yang seringkali disebut juga sebagai koefisien drift yang merupakan penentu arah dari solusi suatu PDS. Fungsi $g(X(t))$ merupakan suku stokastik yang sering kali disebut sebagai koefisien diffusion dengan nilai awal $X_{0}$ yang merepresentasikan fluktuasi dari kurva. Sedangkan fungsi $W(t)$ merupakan proses Wiener yang memiliki karakteristik tertentu merepresentasikan noise/gangguan pada sistem. Secara umum diketahui pula bahwa PDS bersifat nowhere differentiable, yang artinya $\lim _{h \rightarrow 0} \frac{X(t+h)-X(t)}{h}$ tidak ada untuk setiap $t \in[0, T]$. Oleh karena itu solusi eksak dari PDS ini sangat sulit diperoleh dengan pengintegralan deterministik. Apabila disajikan dalam bentuk integral, solusi PDS pada persamaan (1) dapat disajikan sebagai berikut.: 
$X(t)=X(0)+\int_{0}^{T} f(X(t)) d t+\int_{0}^{T} g(X(t)) d W(t)$

dengan $0 \leq t \leq T$.

Bentuk $\int_{0}^{T} f(X(t)) d t$ dari suku ke dua persamaan (2) merupakan integral deterministik dan dapat diselesaikan langsung dengan Integral Riemman, Integral Lebesgue atau integral Henstock. Sedangkan bentuk $\int_{0}^{T} g(X(t)) d W(t)$ dari suku ke tiga dari persamaan (2) merupakan integral stokastik yang diantaranya dapat diselesaikan dengan integral Ito, Integral Stratonovich dan Integral Russo-Vallois dan masih banyak lagi yang lain.

\subsection{Pendekatan Integral Bertipe Stieltjes pada Fungsi Stokastik}

Pendefinisian integral stokastik pada dasarnya berkembang dari integral tipe Stieltjes. Pada integral tipe ini memungkinkan suatu integrator berupa suatu fungsi yang terdefinisi pada interval tertentu, selama fungsi tersebut masih bernilai real. Jadi keberadaan suku $\int_{0}^{T} g(X(t)) d W(t)$ dalam PDS masih memungkinkan diselesaikan dengan integral bertipe Stieltjes. Dalam pengintegralan ini, karakteristik suatu fungsi baik fungsi sebagai integran dan fungsi sebagai integrator merupakan hal penting yang harus diperhatikan agar memenuhi syarat yang diperbolehkan dalam integral bertipe Stieltjes. Berikut akan diberikan contoh tentang kajian integral pada fungsi yang mendekati model geometri dari fungsi stokastik. Contoh yang akan diberikan mengambil permasalahan fungsi gigi gergaji (sawthooth function). Fungsi ini diambil mengingat keberadaan fungsinya menyerupai kondisi fungsi-fungsi stokastik dengan tatanan yang lebih teratur.

Contoh 1. Diberikan fungsi $F:[0,1] \rightarrow \mathfrak{R}$ dengan

$F(x)=\left\{\begin{array}{cl}0, & \text { untuk } x=0 \\ \sum_{k=1}^{n}(-1)^{k+1}\left(\frac{1}{k}\right), & \text { untuk } x=\left(\frac{n}{n+1}\right), n=1,2,3, \ldots \\ \left(\frac{\ln 2,}{F\left(\frac{n}{n+1}\right)-F\left(\frac{n-1}{n}\right)}\right)\left(x-\frac{n-1}{n}\right)+F\left(\frac{n-1}{n}\right), & \text { untuk } x \in\left(\frac{n-1}{n}, \frac{n}{n+1}\right)\end{array}\right.$

Akan diselidiki apakah fungsi turunan dari $F(x)$ terintegral Riemann, Lebesgue atau Henstock? Selanjutnya akan diselidiki pula apakah dengan suatu integrator fungsi yang berdistribusi seragam fungsi tersebut masih terintegral dan integral bertipe Stieltjes masih dipertahankan?

Untuk menjawab hal tersebut pertama-tama akan digambar bentuk geometri dari fungsi $F(x)$ tersebut. Ilustrasi fungsi $F(x)$ dapat dilihat pada gambar 1 berikut:

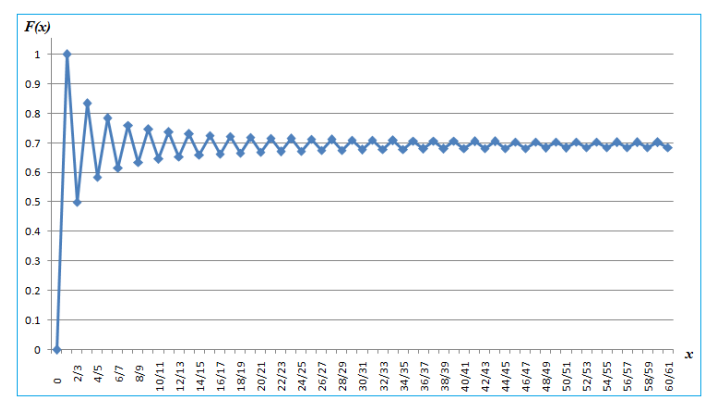

Gambar 1. Grafik fungsi $F(x)$

Dari Gambar 1 diperoleh bahwa

1. Fungsi $F$ fungsi kontinu pada $[0,1]$.

2. Fungsi $F$ terdiferensial kecuali pada $\frac{1}{2}, \frac{2}{3}, \ldots, \frac{n}{n+1}, \ldots$ dengan

$$
f(x)=F^{\prime}(x)=\left\{\begin{array}{cc}
2, & \text { pada }\left(0, \frac{1}{2}\right) \\
-3, & \text { pada }\left(\frac{1}{2}, \frac{2}{3}\right) \\
4, & \text { pada }\left(\frac{2}{3}, \frac{3}{4}\right) \\
\vdots & \vdots \\
(-1)^{n+1}(\mathrm{n}+1), & \text { pada }\left(\frac{n-1}{n}, \frac{n}{n+1}\right)
\end{array}\right.
$$

Ilustrasi fungsi $f(x)$ dapat dilihat pada gambar 2 berikut:

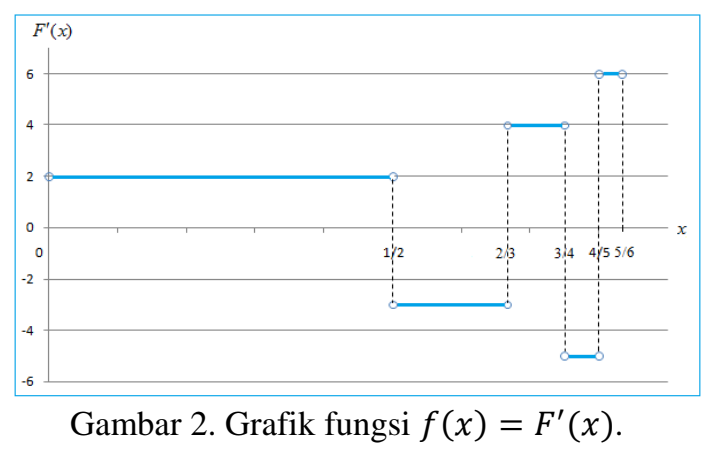

Pada kasus ini fungsi $f(x)$ bersifat diskontinu di berhingga titik apabila $n$ berhingga, akan tetapi akan menjadi fungsi yang diskontinu di tak berhingga titik apabila $n$ bernilai menuju tak berhingga.

Akan diselidiki apakah fungsi turunan dari $F(x)$ yaitu $f(x)$ terintegral Riemann, terintegral 
Lebesgue atau terintegral Henstock. Karena fungsi $f(x)$ diskontinu di tak berhingga titik maka fungsi $f(x)$ tidak terintegral Riemann. Selanjutnya akan diselidiki apakah fungsi terintagral Lebesgue. Fungsi $f$ tidak terintegral Lebesgue pada $[0,1]$.

Bukti: Andaikan $f$ terintegral Lebesgue pada $[0,1]$ maka $|f|$ terintegral Lebesgue pada $[0,1]$. Dengan demikian diperoleh

$$
\begin{aligned}
(L) \int_{0}^{1}|f| d \mu & =(L) \int_{0}^{1}\left|F^{\prime}\right| d \mu=\ln 2>(L) \int_{0}^{\frac{n}{n+1}}\left|F^{\prime}\right| d \mu \\
& =2\left(\frac{1}{2}\right)+3\left(\frac{1}{6}\right)+4\left(\frac{1}{12}\right)+\cdots+(n+1)\left(\frac{1}{n(n+1)}\right) \\
& =1+\frac{1}{2}+\frac{1}{3}+\cdots+\frac{1}{n}>\ln 2
\end{aligned}
$$

Muncul suatu kontradiksi, sehingga pengandaian harus diingkar. Jadi $f$ tidak terintegral Lebesgue pada $[0,1]$.

Lebih lanjut akan diselidiki apakah fungsi $f$ terintegral Henstock pada [0,1]. Diperoleh

$$
(H K) \int_{0}^{1} f d x=(H K) \int_{0}^{1} F^{\prime} d x=F(1)-F(0)=\ln 2 \cdot
$$

Dengan demikian diperoleh bahwa fungsi $f$ terintegral Henstock pada $[0,1]$ dengan nilai integral $\ln 2$.

Selanjutnya akan diselidiki pula apakah dengan suatu integrator fungsi yang berdistribusi seragam fungsi tersebut masih terintegral dan integral bertipe Stieltjes masih dipertahankan Diambil fungsi distribusi seragam $g$ pada interval $[0,1]$ dengan

$$
g(x)=\left\{\begin{array}{l}
0, \text { untuk } x<0 \\
x, \text { untuk } 0 \leq x \leq 1 \\
1, \text { untuk } x>1
\end{array}\right.
$$

Adapun ilustrasi fungsi $g(x)$ dapat dilihat pada gambar 3 berikut:

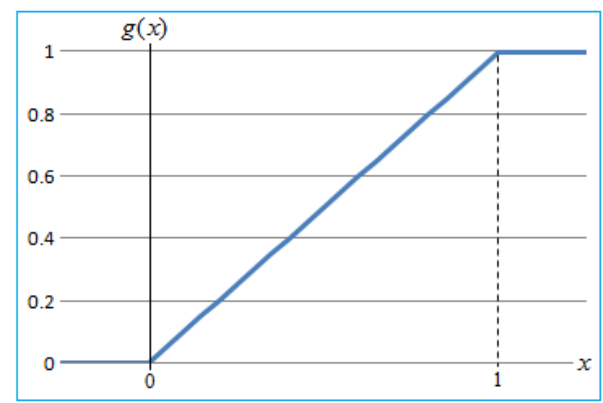

Gambar 3 Grafik fungsi $\mathrm{g}(x)$

Pada kasus ini dapat dilihat bahwa fungsi $g(x)$ kontinu pada $[0,1]$, sehingga fungsi yang berdistribusi seragam tersebut dapat digunakan sebagai integrator pada integral bertipe Stieltjes. Dengan demikian diperoleh nilai hitung dari integral Henstock-Stieltjest yang merupakan nilai harapan dari fungsi $f(x)$ adalah

$$
E(f)=\int_{0}^{1} f(x) d g(x)=F(1) \cdot 1-F(0) \cdot 0=\ln 2-0=\ln 2=0,69315
$$

Dari contoh tersebut dapat diperoleh bahwa fungsi yang diselidiki terintegral HenstockStieltjes dengan integrator fungsi berdistribusi seragam yang kontinu.

Lebih lanjut akan diberikan gambaran terkait langkah penyelidikan apakah suatu PDS memungkinkan didekati dengan penyelesaian integral bertipe Stieltjes. Misalkan diberikan definisi dari fungsi $W(t)$ pada PDS sebagai fungsi gerak Brown Fraksional.

Definisi 2. Diberikan $H \in(0,1)$. Proses stokastik yang didefinisikan sebagai $B^{H}:[0,+\infty) \times \Omega \rightarrow \Re$, dengan $H$ Gaussian bersifat selft similar dan $\sigma^{2}=1$ disebut gerak Brown Fraksional (Fractional Brownian Motion)

Berdasarkan Biagini (2008) Gerak Brown Fraksional $B^{H}$ memiliki modifikasi kontinu dan $B^{H}$ adalah memiliki sifat proses Gaussian Markov untuk $0<H \leq 0,5$. Sedangkan untuk $H>0,5$ Gerak Brown Fraksional tidak bersifat kontinu. Karena Gerak Brown Fraksional dapat bersifat kontinu untuk $0<H \leq 0,5$ maka Gerak Brown Fraksional bervariasi terbatas. Oleh karena itu fungsi Gerak Brown Fraksional untuk $0<H \leq 0,5$ dapat dipakai sebagai integrator untuk integral pada suku ketiga dan persamaan $\quad d S(t)=\mu S(t) d t+\sigma S(t) d W(t)$ sehingga persamaan tersebut dapat diselesaikan dengan integral Stieltjes. Keberadaan fungsifungsi stokastik baik sebagai integran ataupun integrator pada setiap suku PDS harus diselidiki satu persatu sehingga memungkinkan untuk PDS tersebut diselesaikan dengan salah satu integral bertipe Stieltjes. Apabila ingin diketahui tipe integral Stieltjes yang akan digunakan maka diperlukan kajian atau penelitian lebih lanjut terutama terkait pada fungsi integran yang akan diintegralkan yang terdapat pada PDS tersebut.

\section{KESIMPULAN}

Integral stokastik pada dasarnya berkembang dari integral tipe Stieltjes sehingga PDS dapat diselesaiakan dengan pendekatan integral Stieltjes. Keberadaan fungsi stokastik 
baik sebagai integran ataupun integrator pada setiap suku PDS harus diselidiki satu persatu sehingga memungkinkan untuk PDS tersebut diselesaikan dengan salah satu integral bertipe Stieltjes. Kajian lebih lanjut terutama terkait pada fungsi integran yang akan diintegralkan harus dilakukan apabila ingin diketahui tipe integral Stieltjes yang akan digunakan. Dengan mengetahui karakteristik fungsi integran dan fungsi integrator pada PDS diharapkan dapat mempermudah dan memungkinkan dalam mencari solusi eksak suatu PDS.

\section{Ucapan Terima Kasih}

Penulis mengucapkan terima kasih kepada Universitas Udayana, yang telah mendanai Program Unggulan Program Studi (PUPS) ini, melalui pendanaan DIPA BLU Universitas Udayana tahun akademik 2018

\section{DAFTAR PUSTAKA}

Apostol, T.M, 1975, Mathematical Analysis, Addison-Wesley Publishing Company.

Bartle, R.G., 2001, A Modern Theory of Integration, American Mathematical Society, Vol. 32., Providence, Rhode Island.

Biagini, F., Hu, Y., Øksendal, B., Zhang, T. 2008. Stochastic Calculus for Fractional Brownian Motion and Applications. Probability and its Applications. Springer-Verlag London, Ltd., London.
Burk, F.E., 2007, A Garden of Integrals, The Mathematical Association of America, Number Thirty-One.

Burkill,J.C. \& Burkill, H, 1970, A Second Course in Mathematical Analysis, Cambridge University Press, London.

Carter, M. \& Brunt, B.V., 2000, The LebesgueStieltjes Integral A Practical Introduction, Springer-Verlag New York, Inc.

Horst, H.J.T., 1984, Riemann-Stieltjes and Lebesgue-Stieltjes Integrability, The American Mathematical Monthly, Vol. 91, No. 9 (Nov., 1984), pp. 551-559.

Hassler, Uwe. 2016. StochasticProcesses and Calculus An Elementary Introduction with Applications, Springer International Publishing, Switzerland.

Lee P.Y., 1989, Lanzhou Lectures on Henstock Integration, World Scientific, Singapore.

Lee P.Y. \& Výborný, R., 2000, The Integral: An Easy Approach after Kurzweil and Henstock, Cambridge University Press.

Tularam, G.A. 2013. Mathematics in Finance and Economics: Importance of Teaching Higher Order Mathematical Thinking Skills in Finance, E-Journal of Business Education \& Scholarship of Teaching Vol. 7, No. 1, 2013, pp: 43-73. 